\title{
Addition of Curcumin in Dairy Sheep Diet in the Control of Subclinical Mastitis
}

\author{
Antonise Mariely Jaguezeski', Gessica Perin' ${ }^{1}$, Regiane Boaretto Crecencio ${ }^{1}$, \\ Matheus Dellaméa Baldissera' ${ }^{2}$, Lenita Moura Stefani ${ }^{1,3}$ \& Aleksandro Schafer da Silva ${ }^{1,3}$
}

\begin{abstract}
Background: Curcumin, a polyphenol derived from rhizome of Curcuma longa, has been successfully used in animals and humans due to its antibacterial and anti-inflammatory properties. Recently, a study demonstrated that curcumin ointment reduced pain, mammary tension and erythema in humans with mastitis $72 \mathrm{~h}$ after the treatment. Mastitis in sheep is an important problem due to restrictions associated to the use of antibiotics, affecting milk production and becoming a public health issue. Thus, the aim of this study was to verify whether the addition of curcumin in the diet of six female sheep with subclinical mastitis could have curative efficacy and benefits to animal health.

Cases: Six Lacaune sheep with subclinical mastitis that persisted for more than thirty days after the parturition were used. The animals received feed containing the curcumin ( $60 \mathrm{mg} /$ animal/day) during 10 days. On days 0 and 10 of the experiment, total blood was collected to perform the hemogram and serum biochemistry (triglycerides, cholesterol, glucose, total protein (TP), albumin, globulin, aspartate aminotransferase (AST) and urea), as well as individual milk samples for centesimal composition, somatic cell count (SCC) and total bacterial count (TBC). Total leukocytes and erythrocytes, as well as hemoglobin content, were obtained using the hematological counter CELM-CC-550. Blood smears were stained by the Romanowsky method and used for leukocytes differentiation. After ten days of treatment, five sheep were negative in the California Mastitis Test (CMT). Total erythrocytes increased, while total leukocytes decreased after the treatment. Seric levels of AST, triglycerides, cholesterol and globulins decreased, while seric levels of albumin and urea increased after ten days of treatment. No differences were observed regarding milk production and composition, as well as for SCC and TBC on days 0 and 10 post-treatment.

Discussion: The use curcumin to prevent or to delay the occurrence of subclinical mastitis in ewes was first tested. In an experiment of lipopolysaccharide-induced mastitis in rats, researchers identified receptors type Toll 4 which are related with the induction of the synthesis of pro-inflammatory cytokines, as tumor necrosis factor alpha, interleukin- 6 and 1 , molecules involved in the migration of leukocytes to the site of inflammation. According to literature, curcumin was able to reduce the activity of myeloperoxidase in the mammary gland, an enzyme used as indicator of neutrophil infiltration, demonstrating the potent anti-inflammatory effect of curcumin. This effect can be associated to the release of interleukin-8, a cytokine that promotes the migration of neutrophils, lymphocytes and eosinophils into the site of infection, i.e., the mammary gland. It is important to highlight that neutrophils, due to its capacity to release inflammatory mediators and to delay apoptosis, has the potential to maintain a permanent inflammatory process, effects that were prevented or reduced by curcumin, specially the apoptotic and cytotoxic effects. It is important to emphasize the direct effect of curcumin on bacteria present in the mammary gland, since it exerts potent bactericidal effect. In summary, the use of curcumin in sheep with subclinical mastitis exerted beneficial effects in the dose of $60 \mathrm{mg} / \mathrm{sheep} /$ day, since it showed $83.3 \%$ of curative efficacy in the test CMT. This effect of curcumin can be direct or indirect, since the curcumin provided in the diet showed anti-inflammatory properties by reducing oxidation reactions and cell damage. Overall, the addition of curcumin in sheep diet improved the hematological and biochemical variables after only ten days of treatment. Future studies should be performed to clarify and determine whether the curcumin provided in diet can be an alternative to treat clinical or subclinical mastitis.
\end{abstract}

Keywords: curcumin, mammary infection, immunity, biochemistry parameters, ovine. and Parasitology, Universidade Federal de Santa Maria (UFSM), Santa Maria, RS, Brazil. ${ }^{3}$ Department of Animal Science, UDESC, Chapecó. CORRESPONDENCE: A.S. Da Silva [aleksandro.silva@udesc.br - Tel +55 (49) 2049-9560]. Departamento de Zootecnia, Universidade do Estado de Santa Catarina (UDESC). Rua Beloni Trombeta Zanini n. 680E. Bairro Santo Antônio. CEP 89805-030 Chapecó, SC, Brazil. 


\section{INTRODUCTION}

The production of sheep milk and milk products represent a significant source of income in the sheep industry. However, subclinical mastitis is the main issue associated with decreased milk quantity and quality [15], loss of cheese yield and rennet firmness, resulting in economic losses to farmers and dairy industries [18]. The prevalence of subclinical mastitis in sheep varies from 9.23 to $28.1 \%$ [8,15], being the coagulase-negative the most incident agent [15]. According to literature [21], tetracycline and aminoglycosides are the most commonly used antibiotics to combat mammary infections in sheep. However, the use of antibiotics in animals is restricted in several countries due to concerns regarding microbial resistance in animals and humans $[9,19]$, leaving the discard of affected animals as the only alternative. As a consequence, the use of natural compounds in the diet of these animals has gained importance due to their beneficial effects associated to the improvement of animal health and disease resistance, as the use of curcumin [7].

Curcumin, a polyphenol derived from rhizome of Curcuma longa, has been successfully used in animals and humans due to its antibacterial and anti-inflammatory properties [14,27,33]. Recently, a study demonstrated that curcumin ointment reduced pain, mammary tension and erythema in humans with mastitis $72 \mathrm{~h}$ after the treatment [1]. Also, in experimental procedures, the use of curcumin reduced the inflammatory process in lipopolysaccharide-induced mastitis in mice [14]. Therefore, the aim of this study was to evaluate the addition of curcumin in the diet of 6 female sheep with subclinical mastitis regarding its curative effect and benefits to animal health.

\section{CASE}

Six Lacaune sheep (multiparous with 2 to 4 gestations) diagnosed with subclinical mastitis of a dairy farm located in Southern Brazil were used in this study. Subclinical mastitis was diagnosed using the California Mastitis Test (CMT) in the first days after parturition before milking, and the animals remained positives than 30 days. The animals were not treated with antibiotics, since in this farm positive animals are discarded to avoid milk drug residue. After the diagnosis, the animals were transferred to isolated stalls (4 $\mathrm{m} \times 10 \mathrm{~m}$ ) with straw bedding, water ad libitum and individual feeding based on corn silage twice a day. In the beginning of the experiment, the animals were fed with a concentrate ( $300 \mathrm{~g} / \mathrm{sheep}$ ) containing curcumin $(200 \mathrm{mg} / \mathrm{kg}$ of ration $=60 \mathrm{mg}$ curcumin/day/animal $)$ once a day during 10 consecutive days in individual feeders. The concentrate was based on corn and wheat bran in order to obtain $16 \%$ of crude protein, while the curcumin ${ }^{1}$ (98\% of purity) was purchased from China. Physical examination with special attention to the mammary glands was performed in the beginning of the experiment (day 0) and on day day 10. None of the animals showed hyperthermia, swelling or deformities in the mammary gland, which characterize the occurrence of subclinical mastitis when associated to positive CMT test. On days 0 and 10, the CMT was performed based on the protocol stablished [28], being considered positive when the CMT score was above 1.

The quantity of milk produced per sheep was evaluated on days 0 and 10 of the experiment using the Milk Meter ${ }^{2}$ coupled to a mechanical milking pipe. Teats were cleaned and disinfected with alcohol (70\%), and the first three milk jets were discarded, followed by manual collection of milk $(50 \mathrm{~mL})$ in sterile and individual bottles for bacterial total count (TBC). For the centesimal analysis and somatic cell count (SCC), $40 \mathrm{~mL}$ of milk was collected and stored in tubes containing bronopol. Blood sampling was performed on days 0 and 10 of the experiment right before feeding by jugular venipuncture in tubes containing EDTA as anticoagulant $(4 \mathrm{~mL})$ and in tubes without anticoagulant (4 mL). The total blood collected in tubes without anticoagulant was centrifuged at $5600 \mathrm{~g}$ during $10 \mathrm{~min}$, and serum was stored in microtubes at $-20^{\circ} \mathrm{C}$.

The content of fat, protein, lactose, defatted dry extract (DDE), total dry extract (TDE) and SCC was performed by an accredited laboratory using the infrared method according the methodologies defined by the International Dairy Federation (IDF), while the SCC was performed using flow cytometry. For TBC analyses, $1 \mathrm{~mL}$ of each milk sample was serially diluted using buffered peptone water $(1 \%)$ and $1 \mathrm{~mL}$ of each dilution was pour plated using Plate Count Agar (PCA), followed by incubation at $37^{\circ} \mathrm{C}$ for $48 \mathrm{~h}$. The result was expressed as the number of bacterial colony forming unit (CFU).

Total leukocytes and erythrocytes, as well as hemoglobin content, were obtained using the hematological counter ${ }^{3}$. Blood smears were stained by the Romanowsky method and used for leukocytes 
differentiation. The globular volume $(\mathrm{GV})$, as well as the mean corpuscular volume (MCV) and mean corpuscular hemoglobin $(\mathrm{MCH})$, were calculated based on the count of erythrocytes and hemoglobin content, as follows: (MCV $=\mathrm{GV} \times 10$ / erythrocytes); $(\mathrm{MCH}=$ hemoglobin $\times 100 / \mathrm{GV})$. The seric levels of triglycerides, cholesterol, glucose, total protein (TP), albumin, aspartate aminotransferase (AST) and urea were measured in a semi-automatic analyzer ${ }^{4}$ using specific kits ${ }^{5}$ and following the manufacturer's recommendations. Globulin values were obtained by the difference between TP and albumin.

Milk production, composition and quality, as well as hematological and biochemical data were submitted to normality test, and when were not normally distributed, were transformed to logarithm. The Student $t$-test was used to compare the difference between days 0 and 10 , considering $P<0.05$. The results were shown as mean and standard deviation.

Milk volume of treated animals increased approximately 0.1-0.4 L/sheep/day (Figure 1), as well as observed for fat, protein, lactose, DDE, TDE, SCC and TBC (Table 1). After ten days of treatment, five sheep were negative in the CMT test, thus, only 1 sheep remained positive for subclinical mastitis.

In the beginning of study (day 0), total leukocytes was higher compared to reference values, but reduced after curcumin ingestion, which can be directly linked with a reduction on the total count of segmented neutrophils, lymphocytes and eosinophils. On the day 0 , total erythrocytes was lower compared to reference value, but increased on day 10. The $\mathrm{MCH}$ index increased, while the MCV index reduced after the addition of curcumin in the diet (Table 2). Seric levels

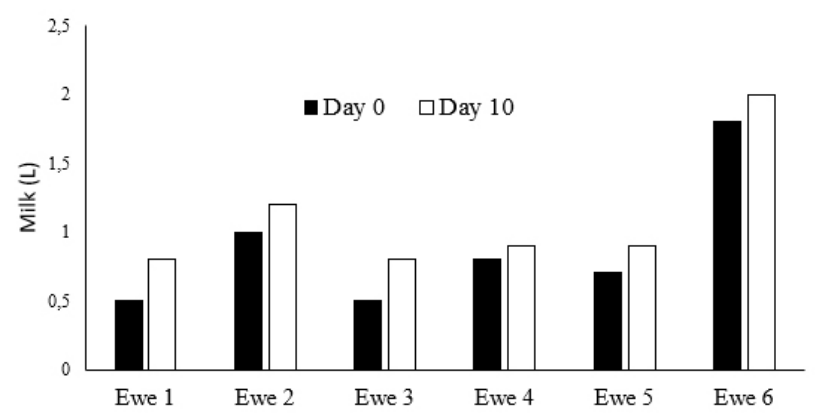

Figure 1. Individual milk production of 6 ewes with subclinical mastitis supplemented with curcumin during 10 consecutive days. No significant difference was observed between day 0 and 10); however, numerically it is possible to verify that milk production increased with the addition of concentrate and curcumin in the diet. Only one sheep was positive in the California Mastitis Test after 10 days of treatment.

of AST, globulins, albumin, cholesterol, triglycerides and urea changed in curcumin treated animals (Table 2). Seric AST activity, as well as globulin and triglycerides levels decreased, while seric levels of albumin and urea increased on day 10 compared to day 0 (Table 2).

\section{DISCUSSION}

In an experiment of lipopolysaccharideinduced mastitis in rats, researchers identified receptors type Toll 4 (TLR4), which are related with the induction of the synthesis of pro-inflammatory cytokines, as tumor necrosis factor alpha (TNF- $\alpha$ ), interleukin-6 (IL-6) and IL-1 $\beta$, molecules involved in the migration of leukocytes to the site of inflammation [20]. The curcumin was able to reduce the activity of myeloperoxidase (MPO) in the mammary gland [35], an enzyme used as indicator of neutrophil infiltration, demonstrating the potent anti-inflammatory effect of

Table 1. Sheep milk production, composition and bacterial count after 0 and 10 days of curcumin dietary supplementation (60 mg/animal/day).

\begin{tabular}{cccc}
\hline Variable & Day 0 & Day 10 & $P$ \\
\hline Production $(\mathrm{L} / \mathrm{day})$ & $0.88 \pm 0.33$ & $1.08 \pm 0.47$ & $>0.05$ \\
Fat $(\mathrm{g} / 100 \mathrm{~g})$ & $7.32 \pm 1.69$ & $7.81 \pm 1.19$ & $>0.05$ \\
Protein $(\mathrm{g} / 100 \mathrm{~g})$ & $4.70 \pm 0.40$ & $4.88 \pm 0.33$ & $>0.05$ \\
Lactose $(\mathrm{g} / 100 \mathrm{~g})$ & $4.35 \pm 0.24$ & $4.38 \pm 0.17$ & $>0.05$ \\
TDE $(\mathrm{g} / 100 \mathrm{~g})$ & $17.36 \pm 1.77$ & $17.95 \pm 1.11$ & $>0.05$ \\
DDE $(\mathrm{g} / 100 \mathrm{~g})$ & $10.04 \pm 0.32$ & $10.11 \pm 0.34$ & $>0.05$ \\
SCC $(\mathrm{x} 1000 / \mathrm{mL})$ & $1094.1 \pm 779.4$ & $836.0 \pm 601.3$ & $>0.05$ \\
TBC $(\mathrm{UFC} / \mathrm{mL})$ & $449.1 \pm 685.1$ & $396.1 \pm 664.3$ & $>0.05$ \\
\hline
\end{tabular}

Results are shown as mean and standard deviation. TDE (total dry extract); DDE (defatted dry extract); SCC (somatic cell count) and TBC (total bacterial count). 
A.M. Jaguezeski, G. Perin, R.B. Crecencio, et al. 2018. Addition of Curcumin in Dairy Sheep Diet in the Control of

Table 2. Hemogram and serum biochemistry of sheep with mastitis after 0 and 10 days of curcumin dietary supplementation ( $60 \mathrm{mg} / \mathrm{animal} / \mathrm{day})$.

\begin{tabular}{ccccc}
\hline Variable & Reference values & Day 0 & Day 10 & $P$ \\
\hline GV $(\%)^{1}$ & $27-45$ & $30.6 \pm 4.1$ & $31.6 \pm 3.8$ & $>0.05$ \\
Erythrocytes $\left(\mathrm{x} 10^{6} / \mu \mathrm{L}\right)^{1}$ & $9.0-15.0$ & $8.6 \pm 1.7$ & $11.5 \pm 0.9$ & $<0.05$ \\
Hemoglobin $(\mathrm{g} / \mathrm{dL})^{1}$ & $9.0-15.0$ & $9.23 \pm 1.21$ & $10.4 \pm 1.8$ & $>0.05$ \\
MCV $(\mathrm{fl})^{1}$ & $28-40$ & $33.07 \pm 4.7$ & $27.4 \pm 1.7$ & $<0.05$ \\
MCH $(\%)^{1}$ & $31-34$ & $29.9 \pm 0.89$ & $32.8 \pm 2.14$ & $<0.05$ \\
Total leukocytes $(\mu \mathrm{L})^{1}$ & $4000-12000$ & $39116 \pm 24499$ & $10341 \pm 3791$ & $<0.05$ \\
Rods $(\mu \mathrm{L})^{1}$ & Rare & $0.0 \pm 0.0$ & $67.5 \pm 80.7$ & $>0.05$ \\
Segmented neutrophils $(\mu \mathrm{L})^{1}$ & $700-6000$ & $19147 \pm 12687$ & $4734 \pm 1654$ & $<0.05$ \\
Lymphocytes $(\mu \mathrm{L})^{1}$ & $2000-9000$ & $14101 \pm 7108$ & $4167 \pm 1850$ & $<0.05$ \\
Monocytes $(\mu \mathrm{L})^{1}$ & $0-750$ & $2818 \pm 2597$ & $947 \pm 320$ & $>0.05$ \\
Eosinophils $(\mu \mathrm{L})^{1}$ & $0-1000$ & $3100 \pm 2416$ & $425 \pm 478$ & $<0.05$ \\
Basophiles $(\mu \mathrm{L})^{1}$ & $0-300$ & $0.0 \pm 0.0$ & $0.0 \pm 0.0$ & $>0.05$ \\
AST $(\mathrm{UL} / \mathrm{L})^{2}$ & $0-90$ & $47.4 \pm 7.8$ & $36.8 \pm 2.7$ & $<0.05$ \\
Total protein $(\mathrm{g} / \mathrm{dL})^{2}$ & $6.0-7.9$ & $7.66 \pm 0.36$ & $7.26 \pm 0.64$ & $>0.05$ \\
Albumin $(\mathrm{g} / \mathrm{dL})^{2}$ & $2.4-3.0$ & $1.93 \pm 0.41$ & $2.4 \pm 0.4$ & $<0.05$ \\
Globulins $(\mathrm{g} / \mathrm{dL})^{2}$ & $3.5-5.7$ & $5.73 \pm 0.56$ & $4.86 \pm 0.67$ & $<0.05$ \\
Cholesterol $(\mathrm{mg} / \mathrm{dL})^{2}$ & $52-76$ & $70.6 \pm 19.3$ & $68.6 \pm 19.1$ & $>0.05$ \\
Triglycerides $(\mathrm{mg} / \mathrm{dL})$ & w/d & $25.1 \pm 6.4$ & $17.6 \pm 3.6$ & $<0.05$ \\
Glucose $(\mathrm{mg} / \mathrm{dL})^{2}$ & $50-80$ & $82.3 \pm 15.3$ & $70.8 \pm 10.8$ & $>0.05$ \\
Urea $(\mathrm{mg} / \mathrm{dL})^{2}$ & $17.12-42.8$ & $22.0 \pm 5.38$ & $29.3 \pm 6.4$ & $<0.05$ \\
\hline
\end{tabular}

Results are shown as mean and standard deviation. GV (globular volume); MCV (mean corpuscular volume); MCH (mean corpuscular hemoglobin), and AST (Aspartate aminotransferase). ${ }^{1}$ Feldman et al. [13]; ${ }^{2}$ Kaneko et al. [17]. w/d = without data in the literature.

curcumin [14]. This effect can be associated to the release of IL-8, a cytokine that promotes the migration of neutrophils, lymphocytes and eosinophils into the site of infection, i.e., the mammary gland [12,32]. Also, other studies have demonstrated that curcumin is able to block the activation of enzymes linked to the release and proliferation of neutrophils, as cyclooxygenase and phospholipases [16,29]. It is important to highlight that neutrophils, due to its capacity to release inflammatory mediators and to delay apoptosis, has the potential to maintain a permanent inflammatory process $[10,34]$, effects that were prevented or reduced by curcumin, especially the apoptotic and cytotoxic effects [3]. These mechanisms can explain the decrease on total leukocyte counts, as well as the numeric decrease on SCC in most animals $(n=4)$. Moreover, it is important to emphasize the direct effect of curcumin on bacteria present in the mammary gland, since it exerts potent bactericidal effect $[7,33]$, contributing to the reduc- tion of the inflammatory process, as occurred in this present study.

Due to the improvement of sheep health, all animals showed a numerical increase on milk volume (Figure 1). This result is important and reinforces the possibility to use curcumin to prevent or to delay the occurrence of subclinical mastitis, since affected animals showed a reduction on performance and consequently important economic losses to milk farms [15]. However, according to researchers [1], increased of milk TBC may not coincide with the clinical manifestation of subclinical mastitis. In this sense, the use of curcumin associated to other natural products may cause a reduction on TBC in milk of cows with subclinical mastitis [9], and in higher doses curcumin improved immunological response and showed anticoccidian effect in lambs $[11,26]$. In summary, higher doses or a more prolonged period of treatment with curcumin may reduce $\mathrm{TBC}$ and $\mathrm{SCC}$. 
The use of curcumin caused a reduction on seric levels of triglycerides and cholesterol, in agreement with literature $[5,26]$. Recently, the use of curcumin was associated with positive effects due to its hypocholesterolemic effects by a reduction on total cholesterol and low-density lipoprotein (LDL) levels, and increase on high-density lipoprotein (HDL) levels, being these results related to the inhibition of enzyme 3-hidroxi-3-methyl-glutaril-CoA reductase (HMGCoA reductase) activity [31]. The use of curcumin in rats with renal damage exerted effect on the reduction of urea and creatinine levels [6], in disagreement to what was observed in this present study. This data may not be linked with curcumin, but with the addition of $300 \mathrm{~g}$ of concentrate in the diet (food not present in the diet before the beginning of experiment), which caused an increase in the synthesis and degradation of proteins, and consequently, increased on albumin and urea levels by metabolic pathways, respectively. Moreover, it is important to emphasize that curcumin avoids the augmentation of AST and alanine aminotransferase (ALT) seric levels in rats intoxicated with lead, demonstrating its hepaprotective properties. In our study, the seric ASAT levels decreased, and remained within the reference values in both sampling times [13].

The consumption of a diet supplemented with curcumin was able to decrease seric globulin levels, as well as observed for total leukocyte count. A study verified that curcumin reduced seric levels of C-reactive protein (CRP) [31], an important inflammatory biomarker produced during acute inflammation [23], infection and tissue damage [25], which may explain the reduction on seric globulin levels in sheep with subclinical mastitis that received curcumin. Moreover, in vitro studies proved the inhibitory effects of curcumin on the proliferation of $\mathrm{T}$ helper lymphocytes and immunoglobulin IgG [30], which also explain the reduction on seric globulin levels.
The increase on erythrocyte count and $\mathrm{MCH}$ index, and the decrease on MCV index, can be linked with indirect effects of curcumin and/or due to the improvement of immune response and inflammatory process. It is important to emphasize that antioxidant enzymes, as catalase (CAT), glutathione peroxidase (GPx) and glutathione S-transferase (GST) were increased in erythrocytes of in animals treated with curcumin [22]. These antioxidants enhance cellular protection and avoid oxidative damage in cell membranes [22,24], which can contribute to augmentation on erythrocyte counts observed in this present study.

The use of curcumin in sheep with subclinical mastitis exerted beneficial effects in the dose of $60 \mathrm{mg} / \mathrm{sheep} /$ day, since it showed $83.3 \%$ of curative efficacy. This effect of curcumin can be direct or indirect, since the curcumin provided in the diet showed anti-inflammatory properties by reducing oxidation reactions and cell damage $[2,4]$. Overall, the addition of curcumin in sheep diet improved the hematological and biochemical variables after only ten days of treatment. Future studies should be performed to clarify and determine whether the curcumin provided in diet can be an alternative to treat clinical or subclinical mastitis.

\section{MANUFACTURERS}

${ }^{1}$ Shanxii Jiahe Phytochem Co. Ltda. Xangai, China. ${ }^{2}$ Openway Ordenhadeiras. Caxias do Sul, RS, Brazil.

${ }^{3}$ Companhia Equipadora de Laboratórios Modernos. Barueri, SP, Brazil.

${ }^{4}$ Bioplus Produtos para Laboratórios Ltda. Barueri, SP, Brazil. ${ }^{5}$ Gold Analisa Diagnóstica Ltda. Belo Horizonte, MG, Brazil.

Declaration of interest. The authors report no conflicts of interest. The authors alone are responsible for the content and writing of the paper.

Acknowledgements. We thank The Scientific and Technological Research Support Foundation of Santa Catarina State (FAPESC) for supporting this study and for granting a scholarship to the first author.

\section{REFERENCES}

1 Afshariani R., Farhadi P., Ghaffarpasand F. \& Roozbeh J. 2014. Effectiveness of topical curcumin for treatment of mastitis in breastfeeding women: A randomized, double-blind, placebo-controlled clinical trial. Oman Medical Journal. 29(5): 330-334.

2 Alvarenga L.A., Leal V.O., Borges N.A., Aguiar A.S., Faxén-Irving G., Stenvinkel P. \& Mafra D. 2018. Curcumin - A promising nutritional strategy for chronic kidney disease patients. The Journal of Functional Foods. 40(4): 715-721.

3 Antoine F., Simard J.C. \& Girard D. 2013. Curcumin inhibits agent-induced human neutrophil functions in vitro and lipopolysaccharide-induced neutrophilic infiltration in vivo. International Immunopharmacology. 17(4): 1101-1107.

4 Aparicio-Trejo O.E., Tapia E., Molina-Jijón E., Medina-Campos O. N., Macías-Ruvalcaba N. A., León-Contre- 
ras J. C., Hernández-Pando R., García-Arroyo F.E., Cristóbal M., Sánchez-Lozada L.G. \& Pedraza-Chaverri J. 2017. Curcumin prevents mitochondrial dynamics disturbances in early $5 / 6$ nephrectomy: Relation to oxidative stress and mitochondrial bioenergetics. Biofactors. 43(2): 293-310.

5 Arshami J., Pilevar M., Azghadi M.A. \& Raji A.R. 2013. Hypolipidemic and antioxidative effects of curcumin on blood parameters, humoral immunity, and jejunum histology in Hy-line hens. Avicenna Journal of Phytomedicine. 3(2): 178-185.

6 Bahram A.T., Daryoush M., Yousef D. \& Saeid S. 2011. Protective effect of turmeric (Curcuma longa linn.) Powder on early diabetic nephropathy in rats. Advances in Environmental Biology. 5(7): 946-951.

7 Baldissera M.D., Souza C.F., Zeppenfeld C.C., Descovi S., Machado V.S., Santos R.C.V. \& Baldisserotto B. 2018. Efficacy of dietary curcumin supplementation as bactericidal for silver catfish against Streptococcus agalactiae. Microbial Pathogenesis. 116(2): 237-240.

8 Beheshti R., Shaieghi J., Eshratkhah B., Ghalehkandi J.G. \& Maheri-Sis N. 2010. Prevalence and etiology of subclinical mastitis in ewes of the Tabriz region, Iran. Global veterinaria. 4(3): 299-302.

9 Bhatt V., Shah T., Nauriyal D., Kunjadia A. \& Joshi C. 2014. Evaluation of a topical herbal drug for its in-vivo immunomodulatory effect on cytokines production and antibacterial activity in bovine subclinical mastitis. An International Quarterly Journal of Research in Ayurveda. 35(2): 198-206.

10 Cascao R., Rosário H.S. \& Fonseca J.E. 2009. Neutrophils: warriors and commanders in immune mediated inflammatory diseases. Acta Reumatológica Portuguesa. 34(2): 313-326.

11 Cervantes-Valencia M.E., Alcalá-Canto Y., Sumano-Lopez H., Ducoing-Watty A.M. \& Gutierrez-Olvera L. 2016. Effects of Curcuma longa dietary inclusion against Eimeria spp. in naturally-infected lambs. Small Ruminant Research. 136(1): 27-35.

12 Erger R.A. \& Casale T.B. 1995. Interleukin-8 is a potent mediator of eosinophil chemotaxis through endothelium and epithelium. American Journal of Physiology-Lung Cellular and Molecular Physiology. 268(1): 117-122.

13 Feldman B.F., Zinkl J.G. \& Jain C.N. 2000. Schalm's Veterinary Hematology. 5th edn. San Diego: Academic Press, pp.932.

14 Fu Y., Gao R., Cao Y., Guo M., Wei Z., Zhou E. \& Zhang N. 2014. Curcumin attenuates inflammatory responses by suppressing TLR4-mediated NF-אB signaling pathway in lipopolysaccharide-induced mastitis in mice. International Immunopharmacology. 20(1): 54-58.

15 Gebrewahid T.T., Abera B.H. \& Menghistu H.T. 2012. Prevalence and etiology of subclinical mastitis in small ruminants of Tigray regional State, north Ethiopia. Veterinary World. 5(2): 103-109.

16 Huang M.T., Ghai G. \& Ho C.T. 2004. Inflammatory process and molecular targets for antiinflammatory nutraceuticals. Comprehensive Reviews in Food Science and Food Safety. 3(4): 127-139.

17 Kaneko J.J., Harvey J.W. \& Bruss M.L. 2008. Clinical biochemistry of domestic animals. New York: Academic press, pp.974.

18 Leitner G., Merin U. \& Silanikove N. 2011. Effects of glandular bacterial infection and stage of lactation on milk clotting parameters: Comparison among cows, goats and sheep. International Dairy Journal. 21(4): 279-285.

19Lollai S.A., Ziccheddu M., Duprè I. \& Piras D. 2016. Characterization of resistance to tetracyclines and aminoglycosides of sheep mastitis pathogens: study of the effect of gene content on resistance. Journal of Applied Microbiology. 121(4): 941-951.

20 Lu Y.C., Yeh W.C. \& Ohashi P.S. 2008. LPS/TLR4 signal transduction pathway. Cytokine. 42(1): 145-151.

21 Marogna G., Rolesu S., Lollai S., Tola S. \& Leori G. 2010. Clinical findings in sheep farms affected by recurrent bacterial mastitis. Small Ruminant Research. 88(2): 119-125.

22 Messarah M., Amamra W., Boumendjel A., Barkat L., Bouasla I., Abdennour C., Boulakoud M.S. \& Feki A.E. 2013. Ameliorating effects of curcumin and vitamin $E$ on diazinon-induced oxidative damage in rat liver and erythrocytes. Toxicology and Industrial Health. 29(1): 77-88.

23 Mold C., Gewurz H. \& Du Clos T.W. 1999. Regulation of complement activation by C-reactive protein. Immunopharmacology. 42: 23-30.

24 Morabito R., Romano O., La Spada G. \& Marino A. 2016. H2O2-induced oxidative stress affects SO4= transport in human erythrocytes. PloS one. 11(1): e0146485.

25 Pepys M.B. \& Hirschfield G.M. 2003. C-reactive protein: a critical update. The Journal of Clinical Investigation. 111(12): 1805-1812. 
A.M. Jaguezeski, G. Perin, R.B. Crecencio, et al. 2018. Addition of Curcumin in Dairy Sheep Diet in the Control of Subclinical Mastitis.

26 Pungcharoenkul K. \& Thongnopnua P. 2011. Effect of different curcuminoid supplement dosages on total in vivo antioxidant capacity and cholesterol levels of healthy human subjects. Phytotherapy Research. 25(10): 1721-1726.

27 Sarkar A., De R. \& Mukhopadhyay A.K. 2016. Curcumin as a potential therapeutic candidate for Helicobacter pylori associated diseases. World Journal of Gastroenterology. 22(9): 2736.

28 Schalm O.W. \& Noorlander D.O. 1957. Experiments and observations leading to development of the California mastitis test. Journal of the American Veterinary Medical Association. 130(5): 199-204.

29Sharma R.A., Gescher A.J. \& Steward W.P. 2005. Curcumin: the story so far. European Journal of Cancer. 41(13): 1955-1968.

30 Sharma S., Chopra K., Kulkarni S.K. \& Agrewala J.N. 2007. Resveratrol and curcumin suppress immune response through CD28/CTLA-4 and CD80 co-stimulatory pathway. Clinical \& Experimental Immunology. 147(1): 155-163.

31 Shin S.K., Ha T.Y., McGregor R.A. \& Choi M.S. 2011. Long-term curcumin administration protects against atherosclerosis via hepatic regulation of lipoprotein cholesterol metabolism. Molecular Nutrition \& Food Research. 55(12): 1829-1840.

32 Taub D.D., Anver M., Oppenheim J.J., Longo D.L. \& Murphy W.J. 1996. T lymphocyte recruitment by interleukin-8 (IL-8). IL-8-induced degranulation of neutrophils releases potent chemoattractants for human T lymphocytes both in vitro and in vivo. The Journal of Clinical Investigation. 97(8): 1931-1941.

33 Teow S.Y., Liew K., Ali S.A., Khoo A.S.B. \& Peh S.C. 2016. Antibacterial action of curcumin against Staphylococcus aureus: a brief review. Journal of Tropical Medicine. DOI: 10.1155/2016/2853045.

34 Wright H.L., Moots R.J., Bucknall R.C. \& Edwards S.W. 2010. Neutrophil function in inflammation and inflammatory diseases. Rheumatology. 49(10): 1618-1631.

35 Zhu W., Gu B., Miao J., Lu J. \& Zou S. 2011. Dectin1 activation of $\beta$-(1-3)/(1-6)-d-glucan produces an anti-mastitis effect in rats. Inflammation Research. 60(10): 937. 